\title{
习习art Thiơ.
}

\section{PERISCOPE.}

\section{PRACTICE OF MEDICINE.}

CONTRIBUTIONS TO THE DOCTRINE OF LRAMIA. BY DR. OPPLER, BERLIN.

When, in the course of Bright's disease, the function of the kidney is gradually abolished, a series of symptoms appears, which have been long known, but which have of late been grouped under the term urcmia, although we have not been able to find in facts a physiological foundation for the theory involved in the term. It was easy to see, and it was long ago recognised, that the question must be decided by chemical analysis; but so long as it was impossible to determine accurately what changes took place in the blood when the kidneys had lost their activity, it was equally impossible to explain the symptoms, or to use rational therapeutic means to oppose them. It was this idea, however, which pointed out to science the way in which it should tread in order to arrive at a solution of the question of uræmia ; and it seems to me that it would be both interesting and important to give a short sketch of the path which has been followed, and of the results which have been gradually arrived at. I will therefore endeavour, in the first place, to bring together the materials which have already been collected.

By the end of the sixteenth century the observations of some authors had become known, from which it appeared that, in patients with hardened kidneys, sudden vomiting, insensibility, and somnolence sometimes made their appearance, as well as other phenomena, which appears to point to uræmia. In the then state of physiology, particularly of physiological chemistry, it was hardly to be expected that any attempt should be made to obtain a rational explanation of these phenomena; a chemical examination of the blood was out of the question; an examination of the urine consisted of no more than its inspection; and to Cotugno belongs the merit of having, at the end of the eighteenth century, first recognised the presence of albumen in the urine of dropsical patients. Later, when chemical science had advanced, and especially after Bright's researches, attention was directed to the composition of the blood in kidney diseases. The result of these inquiries was shortly the following:-The principal change which the blood undergoes consists in the loss of its albumen; this, according to Owen Rees, is sometimes so considerable that the density of the serum, which in health is 1029 to 1031 , falls to 1018 or 1015 . The red blood-globules suffer no great change in the first stage of the disease; as the malady progresses they diminish in such a degree that a pale, anæmic appearance is considered a characteristic symptom of Bright's disease. The fibrin is sometimes increased in the first stage, when inflammatory phenomena are present; at a later period the amount remains normal, although the presence of fibrinous casts in the urine might be expected to lead to a diminution. The fat and salts of the blood do not in general present any special variation. The most important result of the analysis of the blood was the fact that the elements of the urine, especially the urea, accumulate in the blood in proportion to their diminished excretion by the kidneys. It was on this last fact that it was attempted to find an explanation of the so-called uræmic symptoms. Almost all inquirers started from the supposition that the blood was contaminated by elements of the urine. Osborne, however, believed that the cause of the phenomena was a subacute arachnitis; it is clear, however, that the slight thickening and opacity of the arachnoid is not characteristic of uræmia, and, besides, many examinations of persons who have died with uræmic symptoms have shown that this condition is not constant. 
It was soon generally believed that the presence of urea in the blood was the cause of the peculiar symptoms of uræmia; and this belief was founded both upon a consideration of the important part urea plays in the metamorphosis of tissues, and because it was found present in larger quantities in the blood of the uræmic, than any other of the elements of the urine. This idea, however, was soon contradicted by clinical observation and experiment. Owen Rees recorded a case where the blood of a patient, who retained his intelligence to the very last, contained more urea than he had observed in any case of Bright's disease. Christison, and Bright himself, recorded similar cases. The French observers injected large quantities of urea into the blood of dogs and rabbits, without producing any other effect than diuresis. Gallois, indeed, has maintained that by injecting large quantities of urea into the blood of rabbits he has produced uræmic symptoms; but his experiments are not conclusive, as the quantity of urea which he injected was so large, that an equal amount of any other indifferent substance would probably have produced the same effect. Uric acid, also, when injected in the form of its salts, produced negative results. Stannius and Scheven, on the supposition that when urea is injected into the blood of healthy animals it is so speedily discharged by the kidneys as to produce no bad effects, repeated the injections on animals from which the kidneys had been removed; the result of these inquiries, also, was to show that the presence of urea is not the direct cause of uræmic symptoms. At last, the conclusion was come to that the peculiar phenomena were owing to the presence in the blood of the elements of the urine in general; and Vauquelin and Segalas confirmed this experiment, although people were soon convinced that the result of this experiment depended upon the obstruction of the capillaries by the epithelium mixed with the urine, because clear filtered urine produced no bad effect. 'This was the state of matters when Frerichs, in his excellent work on "Bright's Disease," published in 1852, advanced the opinion, founded on clinical observations and experiments on animals, that the phenomena of uræmic intoxication are not due to the accumulation in the blood of urea as such, but to its conversion, by a peculiar ferment, into carbonate of ammonia. However ingenious this theory, and however plausible the observations on which it is founded, it is not able to support a close and unprejudiced examination. The grounds on which this theory is maintained are shortly these :-

1. It is known that under favourable circumstances urea is readily converted into carbonate of ammonia.

2. In the blood of uræmic persons, carbonate of ammonia can constantly be detected.

3. Injections of carbonate of ammonia into the blood of animals produce the symptoms of uræmia.

It is clear that, if these statements be correct, the conclusion that carbonate of ammonia, derived from urea, is the cause of uræmia, can scarcely be called in question. In order to put the matter to the proof, I have undertaken, under the kind direction of Professor Hoppe, in the Chemical Laboratory of the Pathological Institute, a series of experiments, from which I have acquired the conviction, that the second and third of the above statements, and with them the theory founded upon them, are erroneous, and that the source of the uræmic manifestations is to be sought for elsewhere.

As regards the question, whether injections of carbonate of ammonia into the blood of animals produce the symptoms of uræmia, my experiments have taught me that the phenomena of uræmic intoxication are different from those produced by carbonate of ammonia. The most marked characteristic of chronic uræmia consists, as pointed out by the best clinical observers, in a preponderating depression of the cerebral function. A certain sluggishness and drowsiness are soon apparent in the demeanour and features of the patient; this increases into a deep stupor, from which the loudest cries cannot rouse him; the lethargy in. creases, until at length the respiration becomes stertorous, and death ensues. It is only occasionally that clonic convulsions, affecting the whole muscular system, combine themselves with these symptoms; they are not so frequent in 
the chronic as in the acute form of uræmia, which supervenes upon sudden suppression of the urinary secretion; during these, the consciousness is sometimes unaffected (as is recorded in one of Bright's cases); but the scene soon changes, the patient falls into a deep stupor, which announces the approaching end.

If we compare these symptoms with the effects produced by the injection of carbonate of ammonia, a difference will be at once apparent. Whilst in uræmic intoxication the most characteristic symptom is depression of the whole nervous system, we here meet only with the signs of irritation; carbonate of ammonia acts as an irritant as soon as it is introduced into the blood, the animals become restless, they spring into the air, and speedily vomit, violent convulsions follow, which either terminate shortly in the complete restoration of the animal, or in its death. Accordingly, the result of my experiments on this point has been as follows:-I have never been able to produce, by injections of carbonate of ammonia into the blood of animals, that heaviness and drowsiness, that incapability of being roused-in a word, that intense depression of the nervous system - which observations by the bedside and experiments upon animals have led me to consider as the most characteristic and most constant symptom of uræmia; it is only occasionally that convulsions such as carbonate of ammonia produces are combined with the uræmic manifestations; and it is evident that nothing could be more illogical than to conclude from the occasional appearance of the same phenomenon in two series of symptoms, that these two sets of symptoms depend upon the same cause. It is therefore evident that Frerichs' statement, that injections of carbonate of ammonia produce the characteristic symptoms of uræmia, cannot stand minute investigation.

I now turn to the other important question, as to the chemical demonstration of urea and carbonate of ammonia in the blood of uræmic patients, because a series of experiments which I have instituted on this point may perhaps be of interest, as leading to another explanation of the uræmic phenomena. I have experimented upon numerous dogs and rabbits; in the case of the dogs, I have extirpated sometimes one, sometimes both kidneys, at other times I have tied their ureters, in order to produce artificial uræmia; as to the rabbits, I have injected large quantities of urea into their stomachs. Before I describe these experiments, I must say a few words regarding the method of distinguishing urea and carbonate of ammonia in fluids generally, an operation which is undoubtedly one of the most difficult in organic chemistry, and which demands the most scrupulous care. The method which I consider the most certain of those yet known, and which I have employed in my researches, is the following. To the fluid under examination I added two or three times its volume of alcohol, next added a few drops of acetic acid to retain any ammonia which might be present, then filtered, evaporated the filtrate, and exhausted the remainder with ether. Part of the evaporated etherial extract I examined with chloride of platina for ammonia; to another portion I added a few drops of nitric acid, removed the fat and extractive matter with ether, and thus obtained pure nitrate of urea, which I submitted to microscopic and other tests. But I must here remark, that in this method as well as in all those for distinguishing urea from carbonate of ammonia, the precaution must invariably be taken of immediately saturating the fluid to be examined with alcohol; in this way alone is urea deprived of its property of being so readily converted into carbonate of ammonia. Further, in endeavouring to determine whether carbonate of ammonia existed during life in the blood or contents of the stomach of uræmic individuals, the material to be examined should never be taken from the corpse; as soon as life is extinct, decompositions of all kinds are set agoing in the body, and especially in the blood of the uræmic, in which the products of excretion are accumulated, and from this decomposition the urea is the very last substance to be exempt. The researches of J. Vogel have shown how readily ordinary blood, if left for some time to itself, develops ammonia (within twelve hours after death it could be detected); how much more readily must ammonia be developed when materials are present in the 
blood which are so readily decomposed into carbonate of ammonia as urea. In every experiment, therefore, which lays claim to any degree of accuracy both of these conditions should be attended to. It has certainly happened to me when examining in the morning the blood of uræmic animals which had died during the night, to find only pure undecomposed ammonia; but no one should ever rely upon this; and I am convinced that a large number of the observations in which the presence of carbonate of ammoria has been established, owe their result to neglect of these precautions. For proving the presence of carbonate of ammonia in the expired air, a glass rod dipped in muriatic acid is often employed; if white fumes show themselves, it is taken for granted that urea has been converted into carbonate of ammonia. It was long ago known that this reaction was little characteristic of uræmia. In 1852, Giiterbock noticed that in men with carious teeth, or with particles of aliment between the teeth, or who had recently been smoking, fumes of muriate of ammonia could in this way be produced; that in every sick room a cloud is given off from a rod dipt in non-fuming muriatic acid; and that, on the other hand, no such result was produced in the case of a boy lying in a state of stupor, after cholera, whose teeth were quite sound. Logwood is the most certain method of detecting ammonia; by means of this reagent I have compared the blood of uræmic dogs with that of healthy rabbits. A long strip saturated with an infusion of logwood was suspended from a glass rod over the blood of the $\mathrm{dog}$, and a similar one over that of the rabbit; both strips were slightly coloured blue (probably by the ammonia in the atmospheric air), but the reaction of the uræmic blood was no stronger than that of the healthy.

I shall now proceed to state, shortly, my experiments and their results.

1st Experiment.-On the 9 th of January I removed both kidneys from a middle-sized dog, eare being taken not to injure the peritoneum. The dog lay trembling after the operation, and vomited a greenish fluid. Twenty-five hours after the operation, and before the symptoms of uræmia were clearly marked, the dog was killed by cutting his carotid artery, and the blood to be examined was collected in three vessels. From the first portion the amount of fibrin and hæmatin were quantitatively determined; another portion which was to be examined for urea and carbonate of ammonia was saturated with alcohol, and a little acetic acid added; the third portion was weighed and dried in the air-bath for the quantitative analysis of the extractive matters, salts, etc. The liver and the bile were also examined for urea. A complete analysis of the blood was made, and with the following results:-In 1000 parts, water, 741.6 ; fibrin, 1.76 ; albumen and globulin, 230.1 ; hæmatin, 6.820 ; extractive matters, $10 \cdot 283$; salts, $6 \cdot 923$. 'The search for urea and carbonate of ammonia gave the following results:-After a part of the ethereal extract had been treated in the way above described, a whitish precipitate showed itself on the addition of nitric acid; this was allowed to crystallize in a watch-glass, and characteristic crystals of nitrate of urea were obtained. As a farther test, the crystals were treated with carbonate of baryta, and pure urea was obtained. The rest of the ethereal extract was examined with chloride of platina for carbonate of ammonia. At the end of twenty-four hours there was no trace of precipitate. Urea was found in the bile and liver.

$2 d$ Experiment.-On the 27 th of January both ureters of a dog were tied; the $\mathrm{dog}$ soon recovered from the effects of the operation. Forty hours after the operation he began to vomit, became sleepy, and fell into deep stupor, from which he could not be roused. Fifty hours after the operation I opened the carotid and examined the blood and liver, as in the previous experiment. The result of a complete analysis of the blood was as follows:--In 1000 parts, water, 769; fibrin, 4.762; albumen and globulin, 191.642; hæmatin, 11.8; extractive matters, $14 \cdot 38$; salts, $7 \cdot 956$. In the blood, as well as in the liver, a strikingly large quantity of urea was found; there was no trace of carbonate
of ammonia.

$3 d$ Experiment.-On the 10th of February I removed both the kidneys of a dog. On the next day he was lying on his side, in a drowsy condition, vomiting 
large quantities of a bilious fluid; but as the state of stupor was not decided; he was not killed this day, but died during the night, fifty or sixty hours after the operation. A sufficient quantity of blood for analysis was obtained from the heart and large vessels. The result of the analysis was as follows (the fibrin and hæmatin could not be separately estimated):-In 1000 parts, water, 707 ; albumen, globulin, hæmatin, fibrin, 273.36 ; extractive matters, 13.95 ; salts, 6.43. Urea was found in the blood in large quantities. Unmistakable traces of ammonia were also present; for, on the addition of chloride of platina, I found, after some hours, a crystalline precipitate, which proved to be the platino-chloride of ammonium. In the liver, urea only was found.

4th Experiment.-On the 25th of February I injected on three occasions, in the course of forty hours, a quantity of urea which amounted to 3 drachms. After the two first injections the animal was much agitated, the circulation and respiration were accelerated; but he soon recovered, and there appeared to be nothing abnormal in his condition, except that there was some diarrhœa, and that his urine contained much more urea than before. He died suddenly during the third injection, in consequence of some of the fluid entering his lungs. On examining the blood, it was found to contain urea, but there was no trace of carbonate of ammonia; there was an enormous increase in the amount of the extractive matters. In 1000 parts of blood there were 16.8 of extractive matters.

5th Experiment.-The preceding experiment was repeated, and the rabbit was killed six hours after the third injection. The result of the analysis of the blood was precisely as before. In 1000 parts of blood there were 17 of extractive matters.

6th Experiment.-90 grains of urea were injected into the stomach of a crow. Shortly afterwards there was watery diarrhœea, in which the presence of urea was clearly proved. The health of the animal was in no respect impaired.

7 th Experiment.-On the 12th of June I extirpated both the kidneys of a dog. Several hours afterwards vomiting of a greenish biliary matter set in; the vomited matter was kept for analysis. On the morning of the next day the animal lay in a passive condition, from which he could scarcely be roused, and soon after he fell into a deep stupor; there were jerkings of the head and posterior extremities, but no well-pronounced convulsions, which, however, set in towards evening, and he died during the night. The extractive matters in the blood amounted to 13.56 in 1000 parts. In the blood, as well as in the liver, the presence of urea was clearly made out; there was no trace of carbonate of ammonia. In the matter vomited during life I found only undecomposed urea; after repeated experiments, I could not discover any trace of ammonia. On the other hand, on examining the fluid removed from the stomach after death, unmistakable traces of ammonia were found; although here also undecomposed urea could be detected. In the fluid squeezed out of the muscles a proportionally large quantity of urea was found.

8 th Experiment.- On the 24 th of June I removed both the kidneys from a young, strong dog, and then injected into the right jugular vein a solution containing about $2 \frac{1}{2}$ grammes (about 38 grains) of urea. The injection did not appear to have any bad effect upon him. After a time vomiting set in, and on the following day symptoms such as those which had previously followed extirpation of the kidneys showed themselves. The dog lay in a passive state, became insensible, sometimes recovering from this condition, only to fall into it again in a short time. On the 27 th, about sixty-seven hours after the operation, I killed the animal by opening his carotid. A chemical examination gave the following results:-In the matters vomited, and in the blood, much urea, but no carbonate of ammonia, was found; about half a pound of blood contained 0.137 gramme (about 2 grains) of urea. A pound and a half of muscular flesh contained $0 \cdot 167$ gramme ( $2 \frac{1}{2}$ grains) of urea; the liver contained $0 \cdot 11$ gramme ( $1 \frac{7}{1}$ grain) of urea. The extractive matters of the blood were enormously increased, amounting to 30.6 in 1000 parts.

The 9 th was a repetition of the 8 th experiment, and the results were precisely the same. 
The 10th, 11th, and 12th were parallel experiments, suggested by the $2 d$, in which it was observed that more urea was found in the blood after tying the ureters than after removing the kidneys.

10 th Experiment.-On the 8th of July I removed both kidneys from a dog. In a comparatively short time uræmic symptoms manifested themselves; frequent bilious vomiting was followed by deep stupor; fifty hours after the operation the animal was killed. The amount of urea in the blood was determined quantitatively; the muscular substance was examined not only for urea, but for kreatin. The results were as follow:-The contents of the stomach contained pure, undecomposed urea; in 110 cubic centimetres (about $3 \frac{1}{2}$ ounces) of the blood was 0.025 gramme (about 4 grain) of nitrate of urea, there was no trace of carbonate of ammonia; in the liver was found 0.2 gramme ( 3 grains) of nitrate of urea. In the alcoholic and watery extract of two pounds of muscle, numerous large crystals were found; part of these dissolved in absolute alcohol, the greater part were insoluble; from this latter, beautiful yellow crystals of kreatin were obtained, the weight of which amounted to $2 \cdot 2$ grammes (34 grains); a part of the crystals soluble in alcohol contained 0.06 gramme (about 1 grain) of nitrate of urea, another part insoluble in ether contained a large quantity of leucin, which could not, however, be quantitatively estimated. The extractive matters amounted to 18 in 1000 parts.

11 th Experiment.-On the 25th of .July I tied both the ureters of a dog. Thirty hours afterwards he first began to vomit; in about forty-six hours uræmic symptoms set in. He died during the night, from fifty-two to sixty hours after the operation. On examination, various organs, especially the liver and spleen, were found much congested; there was much sanguinolent serum in the pleuræ; the kidneys were much enlarged, the medullary substance was much congested, while the cuticle showed no marks of hyperæmia; the ureters were quite empty. Microscopic examination of the urinary tubules showed them to be widened, and at many places the epithelium was quite gone. I could not obtain enough of pure blood for chemical analysis, but on examining the bloody serum from the pleuræ, there was abundant evidence of the presence of urea; 200 cubic centimetres (nearly $6 \frac{1}{2}$ ounces) contained $0 \cdot 125$ gramme (nearly 2 grains) of nitrate of urea. An examination of the muscular flesh of the animal gave a striking result; a pound and a half was treated in the ordinary manner, and the evaporated alcoholic and watery extract gave a residue which appeared to consist of pure urea; closer examination showed that

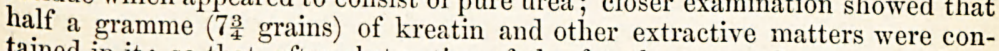
tained in it; so that, after abstraction of the fat, there were 2 grammes (about 31 grains) of pure urea. In the liver and the bile urea was found, but there was none in the kidneys. The presence of carbonate of ammonia was nowhere detected. There were 17 parts of extractive matters in 1000 of blood.

12th Experiment.-On the 7th of August I repeated the 11th experiment; it was long before the dog began to vomit ; fifty hours after the operation,
when symptoms of uræmia had shown themselves, the animal was killed. The kidneys were much enlarged; the left ureter was empty, the right was distended with a fluid which contained much urea. A quantitative examination for urea in the blood showed a large accumulation; 200 cubic centimetres (nearly $6 \frac{1}{2}$ ounces) of blood contained 0.457 gramme ( 7 grains) of nitrate of
urea.

I must now inquire to what conclusions the above detailed experiments lead.

In the first place, I think they show undoubtedly that the decomposition of urea into carbonate of ammonia cannot be regarded as the cause of uræmic phenomena; for neither could I produce these phenomena by the injection of carbonate of ammonia, nor could $I$ in the blood of eight uræmic dogs detect a trace of that substance; in one of the experiments, indeed (the third), a little was found, but as the blood had been taken from the corpse of the animal, the carbonate of ammonia had no doubt been generated after its death. In the second place, chemical examination of the blood, and of the muscles,
has supplied me with two positive facts, which may serve as a foundation for a 
different explanation of the uræmic phenomena. The facts I allude to are, the enormous increase of the extractive matters in the blood, and the large quantity of kreatin and leucin found in the muscles. As I discovered, on examining the blood of animals, which had not survived the operation more than forty or fifty hours, that the extractive matters often reached the amount of 18 or 19 in 1000 , I entertain no doubt that this very considerable increase does not depend upon a simple mechanical retention of matters which in the normal condition should be excreted by the kidneys, but that it is in great part occasioned by decompositions going on in various organs, in consequence of a change in the composition of the blood. In order to arrive at certainty upon this point, I examined muscular flesh, because the products of its decomposition are best known, and are most readily submitted to chemical examination. The result was unequivocal; and the large quantity of kreatin ( 34 grains in 2 pounds) and leucin showed distinctly that abnormal decomposition had been taking place. That the large quantity of kreatin was not merely the result of the impeded secretion from the kidneys, and of that normally contained in muscles, is clearly proved by a comparison with the experiments of Schlossberger and Neubauer, the former of whom found 5 grains of kreatin in 2 pounds of human muscle, while the latter found that the quantity of kreatin secreted by the kidneys in twenty-four hours was $7 \frac{3}{4}$ grains. As it accordingly appears undoubted, that in consequence of the arrest of the function of the kidneys, products of decomposition are formed and accumulate to an abnormal extent in muscles, it may almost with certainty be assumed that in the central organ of the nervous system, which is also exposed to be affected by the abnormal constitution of the blood, similar changes in its chemical composition must take place, although the products of the decomposition of this organ are as yet so little known that we cannot submit them to accurate chemical demonstration, as in the case of the muscles. If, therefore, we assume that products of decomposition are formed and accumulated to an abnormal extent in the brain and spinal marrow, we have, I think, a perfectly satisfactory explanation of uræmic phenomena. The occurrence of important chemical changes is quite sufficient to explain the derangement in the function of the brain, and to account for the characteristic symptoms, such as giddiness, dull headache, unconsciousness, stupor. I therefore consider it an error to explain the occurrence of uræmic phenomena by the supposition that one or other of the elements of the urine, or of its decompositions, is retained in the blood, and acts on the brain in a deleterious manner; but I believe that a chemical change in the central organ of the nervous system is to be considered as the most probable cause of uræmia. With regard to the vomiting which is so characteristic an occurrence in uræmia, I do not consider, as many do, that it is occasioned by irritation of the mucous membrane of the stomach by carbonate of ammonia, derived from the decomposition of urea, because I have often examined the vomited matter, as well as the contents of the stomach from uræmic animals just dead, and I have only found pure undecomposed urea present in large quantity. On the other hand, the fact observed by me, that after ligature of the ureters vomiting appears much later than after extirpation of the kidneys, appears to justify the opinion that uræmic vomiting depends upon a sympathetic irritation of the gastric mucous membrane, the result of irritation of the renal nerves. After ligature of the ureters the vomiting does not set in until the urine, having accumulated in the urinary tubules, produces on all sides pressure and irritation; whereas in extirpation of the kidneys the renal nerves suffer a direct irritation.

I must next consider what conclusions are to be drawn from the parallel experiments 2,10,11, 12. Formerly, as urea could not be detected in normal blood, it was supposed that it was formed in the kidneys, until Prevost and Dumas, and subsequently Gmelin, Mitscherlich, and Tiedemann, showed that it might be found in large quantities in the blood of animals from which the kidneys had been removed. These experiments, as well as a more accurate chemical examination, which shows that urea may be detected, although in small quantity, in healthy blood, have led to the generally received opinion 
that all the urea of the urine is formed in the blood by the oxydation of nitrogenous matter, and that the kidneys only effect its separation. Although the quantity of urea existing in the blood which passed through the kidneys was known to be very small in proportion to the amount found in the urine, this was not considered as any objection to the supposition; for the continual circulation of even a very small quantity of a substance constantly formed by the metamorphosis of the tissues, might at length account for the presence of a large quantity in the urine. In the same way was got rid of the objection founded upon the known fact, that after extirpation of the kidneys a much smaller quantity of urea was found in the blood and in the tissues than would, under normal circumstances, have been eliminated in the same time by the kidneys. Bernard and Barreswil thought that the conversion of urea into carbonate of ammonia accounted for the difference; while others expressed the opinion that, when urea had accumulated to a certain extent in the blood, its farther formation was thereby interfered with. It therefore seemed to be proved that the elements of the urine, especially the urea, arrived ready formed at the kidneys; and Ludwig maintained that the whole process of secretion of urine in the kidneys depended simply upon relations of diffusion, that there was secreted from the glomeruli a very diluted fluid, which contained all the elements of the urine, and that this, in consequence of absorption of water by the capillaries which surround the urinary tubules, was concentrated to the condition of urine. Hoppe, however, showed that this simple theory could not be maintained; for if Ludwig's view of the formation of urine were correct, then, if the concentrated urine of an animal were separated from the blood-serum of the same animal by a membranous partition, no water should pass through from the serum to the urine; but experiment showed that this did take place, and it was therefore evident that the secretion took place in some other way. Now, on considering my parallel experiments regarding the amount of urine in the blood after extirpation of the kidneys, and after ligature of the ureters, I think I have arrived at a result of the highest importance regarding the physiological secretion of the urine-namely, that a large part of the urea which we find in the urine does not arrive ready formed at the kidneys, but that it is formed there. In proof of this, I refer to the results of experiments $2,10,11,12$. After extirpation of the kidneys (exp. 10), 2 pounds of muscle afforded about

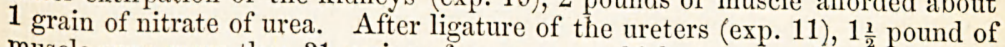
muscle gave more than 31 grains of pure urea, which corresponds to nearly 62 grains of the nitrate. After extirpation of the kidneys (exp. 10), $3 \frac{1}{2}$ ounces of blood gave $\frac{4}{1 a}$ of a grain of nitrate of urea. After ligature of the ureters, $6 \frac{1}{2}$ ounces of blood were found to contain 7 grains of nitrate of urea. How can this great difference be accounted for, except on the supposition that the great excess of urea after ligature of the ureters is the expression of the amount formed independently by the kidneys? I think, therefore, that these facts clearly show that the kidneys are not to be looked upon as the centres of mere processes of diffusion, but that they are to be regarded as having, if not the exclusive, at least a very large independent share in the formation of those substances which are to be considered as the final products of changes which the nitrogenous, especially the albuminous, materials undergo during the process of metamorphosis of the tissues. In what part of the organs this formation has its special seat cannot be determined with certainty. Probably the epithelium plays an important part, as is rendered likely by what we know of the importance of epithelium in other glandular organs; by pathological observations, which show that by destruction of the epithelium the secretion of urine is interfered with; and by the statements of Busch and Wittich, who have found uric acid in the epithelium of the urinary organs of snails and birds. That kreatin plays an important part in the formation of urea is proved by this, - that, after extirpation of the kidneys, 34 grains of kreatin were found in 2 pounds of flesh; while, after ligature of the ureters, $1 \frac{1}{2}$ pound of flesh only contained $7 \frac{3}{4}$ grains. I propose, however, to undertake further researches on this subject. - Virchow's Archiv, Band xxi. Heft 3.1

VOL. VII.-NO. IV. OCTOBER 1861. 
Dr Hammond does not agree with Frerichs in believing that the presence of carbonate of ammonia in the blood is the cause of the symptoms of uræmia : he points out that although severe symptoms are called forth by the injection of this substance into the blood, a fatal result is rarely produced, ammonia being so rapidly evolved by the lungs. Dr Hammond has repeated and modified Frerichs' experiments, and the following are the conclusions at which he has arrived:

$1 s t$, That the injection of urea, in limited quantity, into the blood of animals, produces a certain amount of disturbance in the nervous system, similar in its symptoms to the first stages of uræmia, but that this condition even disappears, if the kidneys are capable of so depurating the blood as to eliminate the toxic substance.

$2 d$, That urea, when introduced into the circulation in larger quantity than can in a limited period be excreted by the kidneys, induces death by uræmia.

$3 d$, That by ligature of the renal arteries, or removal of the kidneys, the elements of the urine being retained in the blood, render this fluid unsuitable to the requirements of the organism, and, consequently induce a condition of system not essentially distinguishable from the uræmic intoxication of Bright's disease, or that caused by the direct introduction of urea into the blood. As, however, was pointed out by Bernard and Barreswil, so long as the urea, or the products of its metamorphosis, are discharged by the stomach or intestines, uræmia does not take place, but, that when these channels become closed, convulsions and coma are produced, and death soon follows.

$4 t h$, That the introduction of urea or urine into the circulation of animals, the kidneys of which have been ablated, shortens the life of such animals, as Frerichs and others have already shown.

5 th, That there is reason to believe that the urine, as a whole, is more poisonous than a simple solution of urea, for, in those cases in which urine was injected into the blood, the amount of urea thus introduced was much smaller than that previously thrown in, in a pure state, and yet symptoms of as great intensity followed.

$6 t h$, That urea, or the elements of the urine, as a whole, induce such a condition of the nervous system, as strongly to predispose to congestion and inflammation of the viscera, especially the lungs, pericardium, and spleen.

7 th, That urea, when directly injected into the blood, or suffered to accumulate in this fluid by extirpation of the kidneys, deranges, in some manner, the process of sanguification, so as to disturb the normal relation of proportion existing between the white and the red corpuscles, and either to hasten the decomposition of these latter, or to interfere with the due removal from the blood of such as are broken down and effete.

$8 t h$, That there is no reason to suppose that, under the circumstances specified, urea undergoes conversion into carbonate of ammonia, but that, on the contrary, there is sufficient evidence to warrant the conclusion that no such process ensues. The fact, that in the foregoing experiments a larger amount of urea was generally found in the blood taken from the body after death, than in that abstracted during life, is, of itself, conclusive against any such hypothesis.-American Journal of the Medical Sciences, January 1861.

\section{MATERIA MEDICA.}

\section{ON THE ELIMINATION OF MERCURY, DURING AND AFTER ITS THERAPEUTIC} EMPLOYMENT. BY PROFESSOR SCHNEIDER, VIENNA.

IT has lately been attempted to revive the old dispute as to the propriety of giving mercury and its preparations as remedial agents. So long as it is unknown whether, and in what quantity, a medicine, after being taken, is discharged from the body, the discussion regarding its effects must necessarily 